\title{
Endoscopic Submucosal Dissection versus Surgery for Undifferentiated-Type Early Gastric Cancer: A Systematic Review and Meta-Analysis
}

\author{
Cheal-Wung Huh ${ }^{1^{*}}$, Dae Won Ma ${ }^{2 *}$, Byung-Wook Kim² ${ }^{2}$ Joon Sung Kim² and Seung Jae Lee ${ }^{3}$ \\ ${ }^{1}$ Department of Internal Medicine, Yongin Severance Hospital, College of Medicine, Yonsei University, Yongin, ${ }^{2}$ Department of Internal \\ Medicine, Incheon St. Mary's Hospital, The Catholic University of Korea, College of Medicine, Incheon, ${ }^{3}$ Medical Library, The Catholic \\ University of Korea, College of Medicine, Seoul, Korea
}

Background/Aims: The use of endoscopic submucosal dissection (ESD) for treating undifferentiated-type early gastric cancer is controversial. The objective of this study was to perform a meta-analysis to compare the long-term outcomes of ESD and surgery for undifferentiated-type early gastric cancer.

Methods: The PubMed, Cochrane Library, and EMBASE databases were used to search for relevant studies comparing ESD and surgery for undifferentiated-type early gastric cancer. The methodological quality of the included publications was evaluated using the Risk of Bias Assessment tool for Nonrandomized Studies. The rates of overall survival, recurrence, adverse event, and complete resection were determined. Odds ratios (ORs) and 95\% confidence intervals (CIs) were also evaluated.

Results: This meta-analysis enrolled five studies with 429 and 1,236 participants undergoing ESD and surgery, respectively. No significant difference was found in the overall survival rate between the ESD and surgery groups (OR, 2.29; 95\% CI, 0.98-5.36; $p=0.06$ ). However, ESD was associated with a higher recurrence rate and a lower complete resection rate. The adverse event rate was similar between the two groups.

Conclusions: ESD with meticulous surveillance esophagogastroduodenoscopy may be as effective and safe as surgery in patients with undifferentiated-type early gastric cancer. Further large-scale, randomized, controlled studies from additional regions are required to confirm these findings. Clin Endosc 2021;54:202-210

Key Words: Endoscopic submucosal dissection; Gastric neoplasm; Meta-analysis; Surgery

\section{INTRODUCTION}

Endoscopic submucosal dissection (ESD) is considered a standard treatment modality for early gastric cancer (EGC) that meets the absolute criteria. ${ }^{1}$ These absolute criteria have

\footnotetext{
Received: April 29, 2020 Revised: June 22, 2020

Accepted: June 27, 2020

Correspondence: Byung-Wook Kim

Division of Gastroenterology, Department of Internal Medicine, Incheon St. Mary's Hospital, The Catholic University of Korea, 56 Dongsu-ro, Bupyeong-gu, Incheon 21431, Korea

Tel: +82-32-280-5051, Fax: +82-32-280-5987, E-mail: gastro@catholic.ac.kr ORCID: https://orcid.org/0000-0002-2290-4954

*These authors contributed equally to this study.

(c) This is an Open Access article distributed under the terms of the Creative Commons Attribution Non-Commercial License (http://creativecommons.org/ licenses/by-nc/3.0) which permits unrestricted non-commercial use, distribution, and reproduction in any medium, provided the original work is properly cited.
}

been expanded by Gotoda et al. based on pathological analysis of surgical specimen for risk factors of lymph node metastasis. ${ }^{2}$ The expanded criteria are now recommended by the Japanese gastric cancer treatment guidelines ${ }^{3}$ and by the Korean guidelines. ${ }^{4}$ Such criteria have been used to determine both the feasibility of ESD and its efficacy for cure. If the efficacy for cure is considered unclear, additional surgery is recommended. Many studies have investigated the feasibility and effectiveness of ESD in treating EGC. ${ }^{5-7}$

Gastric cancers with an undifferentiated histology display different biological behaviors from differentiated-type gastric cancers. They usually show higher lymph node metastasis rates and infiltrative growth. ${ }^{8}$ Recently published meta-analysis studies have revealed that endoscopic resection of EGC is not inferior to surgical resection. ${ }^{9-11}$ Although several studies have reported good long-term survival rates in patients with undif- 
ferentiated-type EGC (UD-EGC) after endoscopic resection, the use of endoscopy rather than surgery for the treatment of UD-EGC is still controversial. ${ }^{12-15}$

No systematic review has been published on the clinical outcomes of ESD compared with surgery in patients with UDEGC. The objective of this study was to perform a systematic review and meta-analysis to clarify the efficacy and safety of ESD and surgery for UD-EGC.

\section{MATERIALS AND METHODS}

\section{Literature searching strategy}

As this article is a systematic review and meta-analysis and does not include the patients' personal information, ethical committee approval was not required. This systematic review and meta-analysis fully adhered to the principles of the Preferred Reporting Items for Systematic reviews and Meta-Analyses (PRISMA) guidelines. ${ }^{16}$ This study was registered in the PROSPERO international database (www.crd.york.ac.uk/ PROSPERO; registration no. CRD42018107853).

The PubMed, Cochrane Library, and EMBASE databases were independently searched by two authors (CWH and DWM). The following search terms were used: "stomach cancer" OR "gastric cancer" OR "early gastric cancer" OR "early stomach cancer" OR "stomach neoplasm and endoscopic resection" OR "endoscopic mucosal resection" OR "endoscopic submucosal dissection" OR "EMR" OR "ESD and gastrectomy" OR "surgery" OR "surgical procedure" OR "general surgery" OR "minimally invasive surgical procedures". No language restrictions were applied. A repetitive manual search of cited references in published studies was performed to identify additional studies.

\section{Selection criteria}

We included studies that met the following criteria: (1) included participants with histologically diagnosed UD-EGC; (2) compared ESD and surgery for the treatment of UD-EGC; and (3) reported results that included at least two of the following endpoints: overall survival, recurrence, adverse event, and complete resection. Studies that met all of these inclusion criteria were sought and selected. The exclusion criteria were as follows: (1) review articles; (2) guidelines or consensus documents or expert position papers; (3) comments, letters, brief reports, and protocol studies; (4) case reports; (5) publications with incomplete data; or (6) meta-analysis articles.

\section{Data extraction}

Two authors (CWH and DWM) independently extracted data from the included studies using a pre-data extraction form. The titles and abstracts of all included studies were reviewed to exclude irrelevant publications. Differing decisions were resolved by consensus. If any clarification of data was necessary, more information was requested from the authors of each study. The following information was extracted: year of publication, name of the first author, sample size, trial inclusion and exclusion criteria, length of follow-up, overall survival rate, recurrence rate, adverse event rate, and complete resection rate. Overall survival rate was defined as the percentage of patients who remained alive after ESD or surgery. Recurrence rate was defined as the percentage of patients who experienced a reappearance of gastric cancer after the initial treatment. Recurrence was defined to include local recurrence, synchronous and metachronous recurrence, and extragastric recurrence. Adverse event was defined as any complication related to the treatment, such as major bleeding, perforation, dehiscence, and infection, during or after the procedure. Complete resection was defined as the total removal of gastric cancer using a surgical or an endoscopic approach without residual viable cells on procedure day.

\section{Methodological quality}

The methodological quality of the included studies was assessed using the Risk of Bias Assessment tool for Nonrandomized Studies (RoBANS). ${ }^{17}$ The RoBANS tool contains six domains. It is a validated tool that is reliable and feasible for assessing the methodological quality of nonrandomized studies. Two authors (CWH and DWM) independently assessed the methodological quality of the included studies. Any disagreement between the two evaluators was resolved by discussion.

\section{Statistical analysis}

Data were analyzed using Review Manager version 5.3 (RevMan for Windows 7; Nordic Cochrane Centre, Copenhagen, Denmark). The adverse events from each study were pooled. Odds ratios (ORs) and 95\% confidence intervals (CIs) of dichotomous variables were obtained using a fixed-effect model or a random-effect model. Heterogeneity was determined using the $I^{2}$ test developed by Higgins et al., ${ }^{18}$ which measures the percentage of total variation across studies. $I^{2}$ was calculated as follows: $I^{2}(\%)=100 \times(\mathrm{Q}-d f) / \mathrm{Q}$, where $\mathrm{Q}$ is Cochrane's heterogeneity statistic and $d f$ is the degree of freedom. Negative values for $I^{2}$ were set to zero, and an $I^{2}$ value of $>50 \%$ was considered to indicate substantial heterogeneity (range, 0\%-100\%). Publication bias was evaluated using Begg's funnel plot and Egger's test of intercept. ${ }^{19,20} \mathrm{~A}$ subsequent assay was performed, excluding outliers. Other findings were compiled. When outliers were not detected, true heterogeneity was presumed. 


\section{RESULTS}

\section{Study selection}

Our search strategy extracted a total of 527 papers (PubMed, $n=156$; Cochrane Library, $n=9$; EMBASE, $n=362)$. Duplicated articles $(n=148)$ were excluded. An additional 349 studies were excluded during the initial screening of titles and abstracts. Thereafter, the full texts of the remaining 30 studies were thoroughly reviewed. Among these studies, 25 articles were excluded from the final analysis for the following reasons: no endpoint of interest $(n=15)$, few patients with UDEGC $(n=8)$, and irrelevant ESD or gastrectomy $(n=2)$. The remaining five studies were included in the final quantitative analysis. The detailed flow diagram illustrating the study selection process is shown in Fig. 1.

\section{Characteristics of the included studies}

The main characteristics of the included studies are listed in Table $1 .^{21-25}$ A total of 1,665 patients were included, with 429 and 1,236 in the ESD and surgery arms, respectively. All articles were retrospective studies from Korea. They were published within the last 5 years (from 2014 to 2019). Chung et al. reported the long-term outcomes of ESD compared with those of surgical treatment in patients with UD-EGC. ${ }^{25}$ They also included some ESD cases that were beyond the expanded indications (23.7\%). The complete resection rates for the absolute criteria group and the beyond criteria group were $86.2 \%$ and $44.4 \%$, respectively $(p<0.05)$. The total recurrence rates in the ESD group and the surgery group were $14.1 \%$ (total, $n=9$; local recurrence, $n=1$; synchronous and metachronous recurrence, $n=7$; extragastric recurrence, $n=1$ ) and $0.7 \%$ (total, $n=1$, metachronous recurrence), respectively $(p<0.05)$. Lee et al. compared the long-term outcomes of ESD and surgery for EGC under the expanded indications based on each criterion. ${ }^{23}$ They selected 522 patients in each group through propensity score matching and retrospectively evaluated each group. In their study, the UD-EGC group showed similar overall survival and recurrence-free survival rates to the other groups. Thus, the authors stated that ESD may be an alternative treatment option to surgery for EGC meeting the expanded indications, including UD-EGC. Hahn et al. aimed to compare the short- and long-term outcomes between ESD and surgery in patients with EGC that fulfilled the expanded criteria for ESD on their final pathological report. ${ }^{24}$ They analyzed 2,203 patients who underwent ESD or surgery for EGC. In the ESD and surgery groups, 92 and 561 patients were
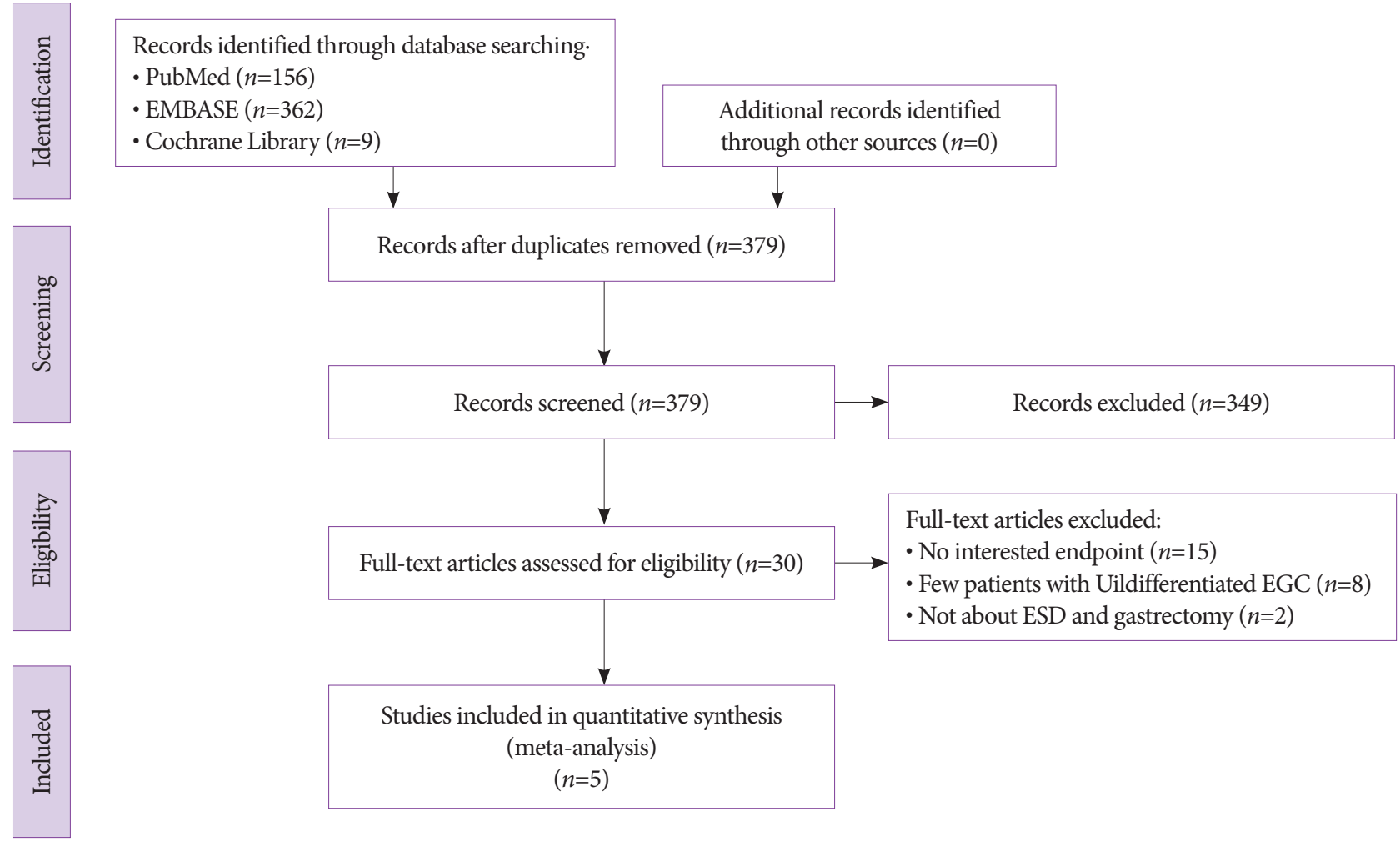

Additional records identified

Fig. 1. Search strategy flowchart. EGC, early gastric cancer; ESD, endoscopic submucosal dissection. 
Table 1. Baseline Characteristics of Included Studies

\begin{tabular}{|c|c|c|c|c|c|}
\hline Study & Study design & Patients & Inclusion criteria & Follow up (mo) & End points \\
\hline $\begin{array}{l}\text { Chung et al. } \\
(2014)^{25}\end{array}$ & Retrospective & $\begin{array}{c}\text { ESD: } 76 \\
\text { Surgery: } 149\end{array}$ & $\begin{array}{c}\text { ESD: EI }(76.3 \%), \\
\text { beyond EI }(23.7 \%) \\
\text { Surgery: EI, no LNM }\end{array}$ & $\begin{array}{c}\text { ESD: } 41.7 \pm 22.6 \\
\text { Surgery: } 42.8 \pm 17.3\end{array}$ & $\begin{array}{l}\text { En bloc resection, complete resec- } \\
\text { tion, complication, recurrence rate, } \\
\text { mortality }\end{array}$ \\
\hline $\begin{array}{l}\text { Lee et al. } \\
(2018)^{23}\end{array}$ & Retrospective & $\begin{array}{c}\text { ESD: } 78 \\
\text { Surgery: } 73\end{array}$ & $\begin{array}{c}\text { ESD: EI } \\
\text { Surgery: EI }\end{array}$ & $\begin{array}{c}\text { ESD: } 52.7(37.7-67.9) \\
\text { Surgery: } 59.2(47.9-63.4)\end{array}$ & $\begin{array}{l}\text { Overall survival, recurrence free } \\
\text { survival, complication, hospital } \\
\text { stay }\end{array}$ \\
\hline $\begin{array}{l}\text { Hahn et al. } \\
(2018)^{24}\end{array}$ & Retrospective & $\begin{array}{c}\text { ESD: } 92 \\
\text { Surgery: } 561\end{array}$ & $\begin{array}{l}\text { ESD: EI } \\
\text { Surgery: EI }\end{array}$ & $\begin{array}{c}\text { ESD: } 37.5(26.3-59.4) \\
\text { Surgery: } 57.3(37.6-60.5)\end{array}$ & $\begin{array}{l}\text { Overall survival, disease-specific } \\
\text { survival, cancer recurrence, com- } \\
\text { plication }\end{array}$ \\
\hline $\begin{array}{l}\text { Park et al. } \\
(2018)^{22}\end{array}$ & Retrospective & $\begin{array}{l}\text { ESD: } 81 \\
\text { Surgery: } 81\end{array}$ & $\begin{array}{l}\text { ESD: EI } \\
\text { Surgery: EI }\end{array}$ & $\begin{array}{c}\text { ESD: } 48.1(33.6-71.4) \\
\text { Surgery: } 60.0(34.0-70.1)\end{array}$ & $\begin{array}{l}\text { Overall survival, disease free surviv- } \\
\text { al, complication, hospital stay, en } \\
\text { bloc resection, complete resection }\end{array}$ \\
\hline $\begin{array}{l}\text { Lim et al. } \\
(2019)^{21}\end{array}$ & Retrospective & $\begin{array}{c}\text { ESD: } 102 \\
\text { Surgery: } 372\end{array}$ & $\begin{array}{l}\text { ESD: EI } \\
\text { Surgery: EI }\end{array}$ & $\begin{array}{c}\text { ESD: } 65.9(48.8-97.4) \\
\text { Surgery: } 58.3(42.3-72.0)\end{array}$ & $\begin{array}{l}\text { Overall survival, disease free sur- } \\
\text { vival, metachronous recurrence, } \\
\text { local recurrence }\end{array}$ \\
\hline
\end{tabular}

EI, expanded indication; ESD, endoscopic submucosal dissection; LNM, lymph node metastasis.

diagnosed with UD-EGC, respectively. The overall survival and disease-specific survival rates were similar between the ESD and surgery groups. However, cancer recurrence was significantly higher in the ESD group than in the surgery group (hazard ratio, 12.801; 95\% CI, 6.074-26.978; $p<0.001$ ). Park et al. showed the long-term outcomes of ESD and surgery for UD-EGC using propensity score analysis. ${ }^{22}$ The clinical data from 111 patients who underwent ESD and 382 patients who underwent surgery were analyzed, and 1:1 propensity scorematched 81 pairs of patients were compared. Overall survival was not significantly different between the two groups in the overall comparison and in propensity score-matched analysis. However, the total recurrence rate was significantly higher in the ESD group than in the surgery group (ESD group, $n=11$ [local recurrence, $n=9$; synchronous and metachronous recurrence, $n=2$ ] vs. surgery group, $n=0)$. Lim et al. showed the long-term outcomes of ESD and surgery for UD-EGC using propensity score matching. ${ }^{21}$ After 1:4 propensity score matching, they compared 102 patients from the ESD group and 372 patients from the surgery group. They included cases that were beyond the expanded indications (ESD: 52.9\%, surgery: $59.7 \%)$. Overall survival and disease-specific survival were similar between the ESD and surgery groups. However, the disease-free survival rate was lower in the ESD group because of the higher rate of metachronous cancer recurrence (hazard ratio, 14.27 ; $95 \% \mathrm{CI}, 3.07-66.31 ; p=0.001)$. Ten patients $(9.8 \%)$ in the ESD group experienced recurrence (local recurrence, $n=4$; metachronous recurrence, $n=6$ ), whereas two patients $(0.5 \%)$ in the surgery group had recurrence (metachronous recurrence, $n=1$; extragastric recurrence, $n=1$ ). In multivariate analysis, treatment option was not related to overall survival (hazard ratio for ESD over surgery, 1.12; 95\% CI, 0.41-3.05; $p=0.831$ ).

\section{Methodological quality}

The methodological quality of the included studies was similar (Fig. 2). One study had a high risk for confounding variables. The study did not show a comparison of baseline

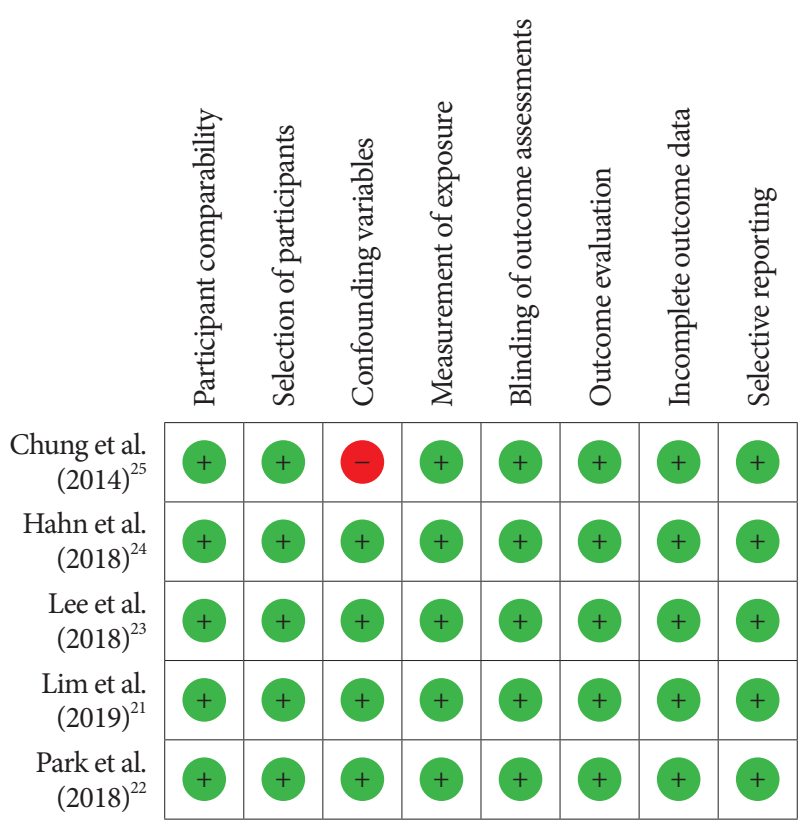

Fig. 2. Risk of bias of the enrolled studies. 
characteristics between two arms. ${ }^{25}$

\section{Comparison of outcomes}

Complete resection data were available for five studies reporting the information of 1,665 patients (Fig. 3). Pooled analysis demonstrated that the complete resection rate was much higher in the surgery group than in the ESD group (OR, 42.86; 95\% CI, 13.06-140.69; $p<0.001)$. The heterogeneity was low $\left(I^{2}=11 \%\right)$.

Adverse event data were available for three studies reporting the information of 966 patients (Fig. 4). Pooled analysis re- vealed that the adverse event rate was similar between the ESD and surgery groups (OR, 0.48; 95\% CI, $0.20-1.13 ; p=0.09$ ). The heterogeneity was high $\left(I^{2}=80 \%\right)$. A funnel plot was drawn, and one outlier was detected. ${ }^{24}$ After excluding this study, heterogeneity persisted $\left(I^{2}=69 \%\right)$. When a random-effect model was applied, the same finding was obtained.

Recurrence data were available for five studies reporting the information of 1,653 patients (Fig. 5). Pooled analysis demonstrated that the recurrence rate was much higher in the ESD group than in the surgery group (OR, 15.82; 95\% CI, 7.03-35.60; $p<0.001)$. The heterogeneity was low $\left(I^{2}=0 \%\right)$.

\begin{tabular}{|c|c|c|c|c|c|c|}
\hline \multirow[b]{2}{*}{ Study } & \multicolumn{2}{|c|}{ Surgery } & \multicolumn{2}{|c|}{ ESD } & \multicolumn{2}{|r|}{ Odds ratio } \\
\hline & Events & Total & Events & Total & Weight & M-H, Random, $95 \% \mathrm{CI}$ \\
\hline Chung et al. $(2014)^{25}$ & 149 & 149 & 58 & 76 & $18.2 \%$ & $94.56[5.61,1,594.66]$ \\
\hline Hahn et al. $(2018)^{24}$ & 561 & 561 & 79 & 92 & $18.1 \%$ & $90.70[11.23,3,239.31]$ \\
\hline Lee et al. $(2018)^{23}$ & 73 & 73 & 77 & 78 & $14.4 \%$ & $2.58[0.11,70.96]$ \\
\hline Park et al. $(2018)^{22}$ & 81 & 81 & 73 & 81 & $17.7 \%$ & $18.85[1.07,332.31]$ \\
\hline Lim et al. $(2019)^{21}$ & 371 & 372 & 88 & 102 & $31.7 \%$ & $59.02[7.66,454.84]$ \\
\hline Total $(95 \% \mathrm{CI})$ & & 1,236 & & 429 & $100.0 \%$ & $42.02[11.74,150.36]$ \\
\hline Total events & 1,235 & & 375 & & & \\
\hline \multicolumn{7}{|c|}{ Heterogeneity: $\mathrm{Tau}^{2}=0.25 ; \mathrm{Chi}^{2}=4.53, \mathrm{df}=4(p=0.34) ; I^{2}=12 \%$} \\
\hline Test for overall effect: & $=5.75(p<1$ & 0001) & & & & \\
\hline
\end{tabular}

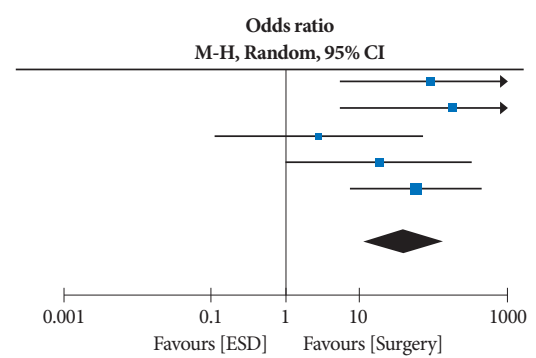

Fig. 3. Forest plot of complete resection rate comparing endoscopic submucosal dissection (ESD) and surgery. $\mathrm{Cl}$, confidence interval.

\begin{tabular}{|c|c|c|c|c|c|c|}
\hline \multirow[b]{2}{*}{ Study } & \multicolumn{2}{|c|}{ Surgery } & \multicolumn{2}{|c|}{ ESD } & \multirow[b]{2}{*}{ Weight } & \multirow{2}{*}{$\begin{array}{c}\text { Odds ratio } \\
\text { M-H, Random, } 95 \% \mathrm{CI}\end{array}$} \\
\hline & Events & Total & Events & Total & & \\
\hline Hahn et al. $(2018)^{24}$ & 3 & 92 & 94 & 561 & $37.1 \%$ & $0.17[0.05,0.54]$ \\
\hline Lee et al. $(2018)^{23}$ & 3 & 78 & 4 & 73 & $34.1 \%$ & $0.69[0.15,3.19]$ \\
\hline Park et al. $(2018)^{22}$ & 7 & 81 & 1 & 81 & $28.8 \%$ & $7.57[0.91,62.98]$ \\
\hline Total $(95 \% \mathrm{CI})$ & & 251 & & 751 & $100.0 \%$ & $0.81[0.11,6.07]$ \\
\hline Total events & 13 & & 99 & & & \\
\hline \multicolumn{7}{|c|}{ Heterogeneity: $\mathrm{Tau}^{2}=2.48 ; \mathrm{Chi}^{2}=9.84, \mathrm{df}=2(p=0.007) ; I^{2}=80 \%$} \\
\hline Test for overall effect & $=0.20(p=$ & & & & & \\
\hline
\end{tabular}

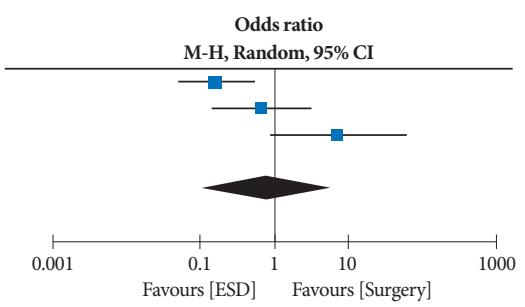

Fig. 4. Forest plot of adverse event rate comparing endoscopic submucosal dissection (ESD) and surgery. Cl, confidence interval.

\begin{tabular}{lcccccc} 
& \multicolumn{2}{c}{ Surgery } & \multicolumn{2}{c}{ ESD } & & Odds ratio \\
Study & Events & Total & Events & Total & Weight & M-H, Random, 95\% CI \\
\hline Chung et al. $(2014)^{25}$ & 9 & 64 & 1 & 149 & $15.1 \%$ & $24.22[3.00,195.61]$ \\
Park et al. $(2018)^{22}$ & 11 & 81 & 0 & 81 & $8.1 \%$ & $26.59[1.54,459.34]$ \\
Hahn et al. $(2018)^{24}$ & 8 & 92 & 3 & 561 & $36.3 \%$ & $17.71[4.61,68.10]$ \\
Lee et al. $(2018)^{23}$ & 3 & 78 & 1 & 73 & $12.6 \%$ & $2.88[0.29,28.33]$ \\
Lim et al. $(2019)^{21}$ & 10 & 102 & 2 & 372 & $27.9 \%$ & $20.11[4.33,93.35]$ \\
Total $(\mathbf{9 5 \%}$ CI) & & 417 & & $\mathbf{1 2 3 6}$ & $\mathbf{1 0 0 . 0 \%}$ & $\mathbf{1 5 . 8 2}[\mathbf{7 . 0 3}, \mathbf{3 5 . 6 0}]$ \\
Total events & 41 & & 7 & & & \\
Heterogeneity: Tau $^{2}=0.00 ; \mathrm{Chi}^{2}=2.54, \mathrm{df}=4(p=0.64) ; I^{2}=0 \%$ & & & \\
Test for overall effect: $\mathrm{Z}=6.67(p<0.00001)$ & & & &
\end{tabular}

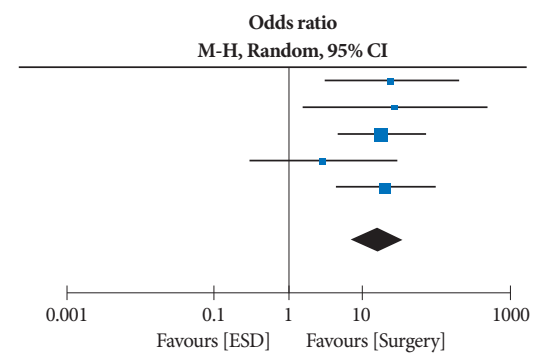

Fig. 5. Forest plot of recurrence rate comparing endoscopic submucosal dissection (ESD) and surgery. Cl, confidence interval. 
Overall survival data were available for four studies reporting the information of 1,491 patients (Fig. 6). The pooled analysis revealed that the overall survival rate was similar between the ESD and surgery groups (OR, 2.29; 95\% CI, 0.98-5.36; $p=0.06)$. The heterogeneity was low $\left(I^{2}=0 \%\right)$.

We also performed subgroup analysis among studies with- in the expanded indications. ${ }^{21}$ In this subgroup analysis, the overall survival rate was similar between the ESD and surgery groups (OR, 1.83; 95\% CI, $0.55-6.12$; $p=0.33$ ). The ESD group showed a higher recurrence rate and a lower complete resection rate than the surgery group (Fig. 7).

\begin{tabular}{|c|c|c|c|c|c|c|}
\hline \multirow[b]{2}{*}{ Study } & \multicolumn{2}{|c|}{ Surgery } & \multicolumn{2}{|c|}{ ESD } & \multirow[b]{2}{*}{ Weight } & Odds ratio \\
\hline & Events & Total & Events & Total & & M-H, Random, 95\% CI \\
\hline Chung et al. $(2014)^{25}$ & 147 & 149 & 64 & 64 & $7.8 \%$ & $0.46[0.02,9.66]$ \\
\hline Hahn et al. $(2018)^{24}$ & 555 & 561 & 89 & 92 & $36.6 \%$ & $3.12[0.77,12.69]$ \\
\hline Lee et al. $(2018)^{23}$ & 73 & 73 & 78 & 78 & & Not estimable \\
\hline Lim et al. $(2019)^{21}$ & 364 & 372 & 97 & 102 & $55.6 \%$ & $2.35[0.75,7.33]$ \\
\hline Total $(95 \% \mathrm{CI})$ & & 1,155 & & 336 & $100.0 \%$ & $2.29[0.98,5.36]$ \\
\hline Total events & 1,139 & & 328 & & & \\
\hline \multicolumn{7}{|c|}{ Heterogeneity: $\mathrm{Tau}^{2}=0.00 ; \mathrm{Chi}^{2}=1.30, \mathrm{df}=2(p=0.52) ; I^{2}=0 \%$} \\
\hline Test for overall effect & $=1.91(p=c$ & & & & & \\
\hline
\end{tabular}

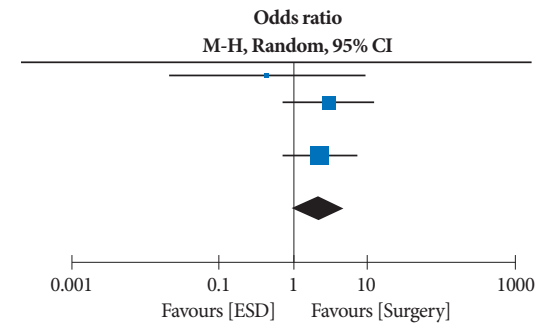

Fig. 6. Forest plot of overall survival rate comparing endoscopic submucosal dissection (ESD) and surgery. $\mathrm{Cl}$, confidence interval.

\begin{tabular}{|c|c|c|c|c|c|c|}
\hline \multirow[b]{2}{*}{ Study } & \multicolumn{2}{|c|}{ Surgery } & \multicolumn{2}{|c|}{ ESD } & \multirow[b]{2}{*}{ Weight } & Odds ratio \\
\hline & Events & Total & Events & Total & & M-H, Random, 95\% CI \\
\hline Lee et al. $(2018)^{23}$ & 73 & 73 & 78 & 78 & & Not estimable \\
\hline Hahn et al. $(2018)^{24}$ & 555 & 561 & 89 & 92 & $74.5 \%$ & $3.12[0.77,12.69]$ \\
\hline Lim et al. $(2019)^{21}$ & 277 & 282 & 48 & 48 & $25.5 \%$ & $0.52[0.03,9.56]$ \\
\hline Total $(95 \% \mathrm{CI})$ & & 916 & & 218 & $100.0 \%$ & $1.98[0.40,9.66]$ \\
\hline Total events & 905 & & 215 & & & \\
\hline
\end{tabular}

(A) Test for overall effect: $\mathrm{Z}=0.84(p=0.40)$

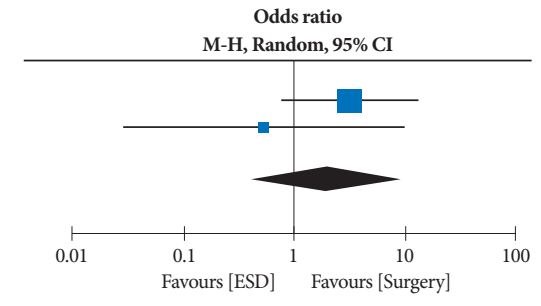

\begin{tabular}{|c|c|c|c|c|c|c|}
\hline \multirow[b]{2}{*}{ Study } & \multicolumn{2}{|c|}{ Surgery } & \multicolumn{2}{|c|}{ ESD } & \multirow[b]{2}{*}{ Weight } & Odds ratio \\
\hline & Events & Total & Events & Total & & M-H, Random, $95 \%$ CI \\
\hline Lee et al. $(2018)^{23}$ & 3 & 78 & 1 & 73 & $18.5 \%$ & $2.88[0.29,28.33]$ \\
\hline Park et al. $(2018)^{22}$ & 11 & 81 & 0 & 81 & $11.9 \%$ & $26.59[1.54,459.34]$ \\
\hline Hahn et al. $(2018)^{24}$ & 8 & 92 & 3 & 561 & $53.2 \%$ & $17.71[4.61,68.10]$ \\
\hline Lim et al. $(2019)^{21}$ & 2 & 48 & 1 & 282 & $16.5 \%$ & $12.22[1.09,137.48]$ \\
\hline Total $(95 \% \mathrm{CI})$ & & 299 & & 997 & $100.0 \%$ & $12.51[4.68,33.39]$ \\
\hline Total events & 24 & & 5 & & & \\
\hline \multicolumn{7}{|c|}{ Heterogeneity: $\mathrm{Tau}^{2}=0.00 ; \mathrm{Chi}^{2}=2.11, \mathrm{df}=3(p=0.55) ; I^{2}=0 \%$} \\
\hline Test for overall effect & $=5.04(p<1$ & $001)$ & & & & \\
\hline
\end{tabular}

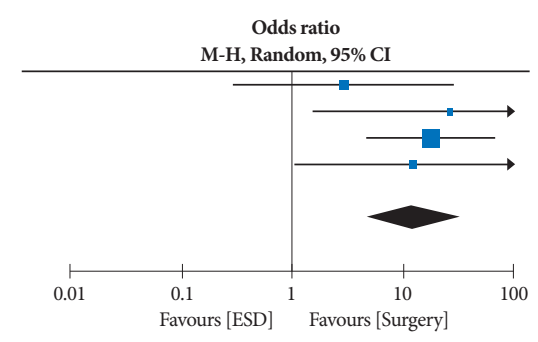

\begin{tabular}{|c|c|c|c|c|c|c|}
\hline \multirow[b]{2}{*}{ Study } & \multicolumn{2}{|c|}{ Surgery } & \multicolumn{2}{|c|}{ ESD } & \multirow[b]{2}{*}{ Weight } & Odds ratio \\
\hline & Events & Total & Events & Total & & M-H, Random, $95 \% \mathrm{Cl}$ \\
\hline Hahn et al. $(2018)^{24}$ & 561 & 561 & 79 & 92 & $35.0 \%$ & $190.70[11.23,3,239.31]$ \\
\hline Park et al. $(2018)^{22}$ & 81 & 81 & 73 & 81 & $34.5 \%$ & $18.85[1.07,332.31]$ \\
\hline Lee et al. $(2018)^{23}$ & 73 & 73 & 77 & 78 & $30.5 \%$ & $2.85[0.11,70.96]$ \\
\hline Total $(95 \% \mathrm{CI})$ & & 715 & & 251 & $100.0 \%$ & $23.77[2.23,252.83]$ \\
\hline Total events & 715 & & 229 & & & \\
\hline
\end{tabular}

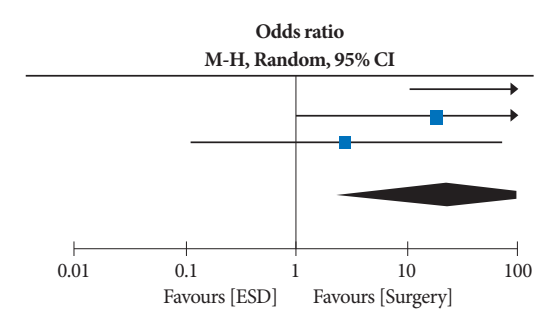

Fig. 7. Subgroup analysis in undifferentiated-type early gastric cancer within the expanded indications. (A) Forest plot of overall survival rate. (B) Forest plot of recurrence rate. (C) Forest plot of complete resection rate. $\mathrm{Cl}$, confidence interval; ESD, endoscopic submucosal dissection. 


\section{DISCUSSION}

ESD is currently considered the standard treatment for EGC that meets the absolute criteria of the Japanese gastric cancer treatment guidelines. ${ }^{3,4}$ However, these absolute criteria might be too strict, leading to unnecessary surgeries. This has resulted in the expansion of the criteria. ${ }^{6,26,27}$ On the basis of retrospective studies on surgical resection of EGC, expanded criteria have been established. ${ }^{2,3,7}$ Unfortunately, there are discrepancies between pre- and post-ESD indications or histology. $^{28-30}$ ESD performed according to the expanded criteria can be beyond the expanded criteria after the procedure. A more serious problem is the difficulty in determining the tumor extent and the depth of invasion of UD-EGC. The accuracy of endoscopic ultrasound for estimating the depth of invasion in UD-EGC is known to be lower than that in differentiated-type EGC. ${ }^{31}$ It is difficult to accurately define the tumor extent and depth of invasion in UD-EGC.

In our meta-analysis, the overall survival rate was similar between the ESD and surgery groups. However, the recurrence rate was much higher in the ESD group. Most previous studies reported that the overall survival rate of patients with UD-EGC treated with ESD was approximately $90 \%$ until the end of follow-up. ${ }^{14,32-34}$ The interval of surveillance with esophagogastroduodenoscopy after ESD and after surgery was not identical in most studies. In the current study, the most common recurrence type in the ESD group was metachronous recurrence. Repeated ESD is an effective treatment modality for local and metachronous recurrence. Surgery is also a successful treatment modality, especially in the presence of regional lymph node recurrence. ${ }^{35}$ Several studies have revealed that metachronous lesions can be effectively detected by endoscopic surveillance in the early stage and cured by repeated ESD or surgery. ${ }^{28,36}$ This may be the reason why the overall survival rate in the ESD group was not inferior to that in the surgery group, although the ESD group had a higher recurrence rate. This suggests that meticulous surveillance after ESD may be as effective and safe as surgery in patients with UD-EGC. Although the overall survival was not significantly different between the ESD and surgery groups, the surgery group tended to have better overall survival (OR, 2.29; 95\% CI, 0.98-5.36; $p=0.06$ ). Conversely, this tendency was significantly decreased in subgroup analysis among patients with UD-EGC within the expanded indications (OR, 1.83; 95\% CI, 0.55-6.12; $p=0.33$ ). Therefore, more meticulous surveillance may be needed, especially for UD-EGC beyond the expanded indications.

Surgery is generally considered to be associated with more adverse events than ESD. However, in the present study, no difference in adverse events was observed between the two groups. Significant heterogeneity existed among the enrolled studies. ${ }^{22-24}$ The pooled adverse event rate for endoscopic resection was $5.7 \%$, with bleeding and perforation being the most common complications. Most cases of bleeding and perforation can be conservatively managed with electrocoagulation, insulated-tip knife, or metal clips. Uncontrolled bleeding or perforation may require surgery. In contrast, complications associated with gastrectomy, including dehiscence, major bleeding, and infection, can lead to mortality. It should be remembered that not all the complications after surgery were described in each study included in this meta-analysis, suggesting that surgical complication rates may have been underestimated. For example, delayed complications after surgery, such as stricture and leakage from the anastomosis site, were not fully described.

Although this is the first systematic review and meta-analysis to compare ESD and surgery for UD-EGC, it had several limitations. First, all included studies were retrospective in nature without randomization, meaning that clinicopathological characteristics such as invasion depth, histological differentiation, and tumor size could not be perfectly matched. This could lead to considerable selection bias. Second, UDEGC included poorly differentiated adenocarcinoma, signet ring cell carcinoma, and mucinous adenocarcinoma. ${ }^{37}$ Poorly differentiated adenocarcinoma and mucinous adenocarcinoma are known to be associated with higher lymph node metastasis than signet ring cell carcinoma. ${ }^{38-40}$ Thus, incomplete pathological subgroup analysis might have affected the results. Third, the included studies were all from Korea, where the incidence of gastric cancer and the detection rate of EGC are relatively high. The situation in Western countries remains unknown. Further studies from other countries are needed to validate the results of our study. Fourth, some data, including overall survival rate and adverse event rate, were not provided in some studies, which weakened the interpreting power of our results. Fifth, because there was high heterogeneity in some analyses, care should be taken when interpreting our results. Finally, we could not evaluate publication bias owing to the small number of studies included. As a rule of thumb, tests for publication bias should be used only when at least 10 studies are included in the meta-analysis.

In conclusion, this meta-analysis showed that ESD with meticulous surveillance esophagogastroduodenoscopy may be as effective and safe as surgery in patients with UD-EGC, especially for cases within the expanded criteria. Further largescale randomized, controlled studies from additional regions are required to confirm these findings. 
Conflicts of Interest

The authors have no potential conflicts of interest.

Funding

None.

Author Contributions

Conceptualization: Byung-Wook Kim

Data curation: Cheal-Wung Huh, Dae Won Ma

Formal analysis: $\mathrm{CWH}$, DWM

Investigation: $\mathrm{CWH}, \mathrm{DWM}$, BWK, Joon Sung Kim, Seung Jae Lee

Methodology: CWH, DWM, BWK, JSK, SJL

Project administration: BWK

Resources: CWH, DWM, JSK, SJL

Software: CWH, DWM

Supervision: BWK

Validation: BWK

Visualization: CWH, DWM

Writing-original draft: $\mathrm{CWH}, \mathrm{DWM}$

Writing-review\&editing: BWK, JSK

\section{ORCID}

Cheal-Wung Huh:

Dae Won Ma:

Byung-Wook Kim:

Joon Sung Kim:

Seung Jae Lee:

\begin{abstract}
https://orcid.org/0000-0001-7327-8503 https://orcid.org/0000-0002-0321-1140 https://orcid.org/0000-0002-2290-4954 https://orcid.org/0000-0001-9158-1012 https://orcid.org/0000-0003-0072-3818
\end{abstract}

\section{REFERENCES}

1. Tsujitani S, Oka S, Saito H, et al. Less invasive surgery for early gastric cancer based on the low probability of lymph node metastasis. Surgery 1999;125:148-154.

2. Gotoda T, Yanagisawa A, Sasako M, et al. Incidence of lymph node metastasis from early gastric cancer: estimation with a large number of cases at two large centers. Gastric Cancer 2000;3:219-225.

3. Japanese Gastric Cancer Association. Japanese gastric cancer treatment guidelines 2010 (ver. 3). Gastric Cancer 2011;14:113-123.

4. Park CH, Yang DH, Kim JW, et al. Clinical practice guideline for endoscopic resection of early gastrointestinal cancer. Clin Endosc 2020;53:142-166.

5. Lee $\mathrm{H}$, Yun WK, Min BH, et al. A feasibility study on the expanded indication for endoscopic submucosal dissection of early gastric cancer. Surg Endosc 2011;25:1985-1993.

6. Ahn JY, Jung HY, Choi KD, et al. Endoscopic and oncologic outcomes after endoscopic resection for early gastric cancer: 1370 cases of absolute and extended indications. Gastrointest Endosc 2011;74:485-493.

7. Hirasawa T, Gotoda T, Miyata S, et al. Incidence of lymph node metastasis and the feasibility of endoscopic resection for undifferentiated-type early gastric cancer. Gastric Cancer 2009;12:148-152.

8. Aihara R, Mochiki E, Kamiyama Y, Kamimura H, Asao T, Kuwano H. Mucin phenotypic expression in early signet ring cell carcinoma of the stomach: its relationship with the clinicopathologic factors. Dig Dis Sci 2004;49:417-424.

9. Sun K, Chen S, Ye J, et al. Endoscopic resection versus surgery for early gastric cancer: a systematic review and meta-analysis. Dig Endosc 2016;28:513-525.

10. Meng FS, Zhang ZH, Wang YM, Lu L, Zhu JZ, Ji F. Comparison of endoscopic resection and gastrectomy for the treatment of early gastric cancer: a meta-analysis. Surg Endosc 2016;30:3673-3683.
11. Kondo A, de Moura EG, Bernardo WM, et al. Endoscopy vs surgery in the treatment of early gastric cancer: systematic review. World J Gastroenterol 2015;21:13177-13187.

12. Bang CS, Baik GH, Shin IS, et al. Endoscopic submucosal dissection for early gastric cancer with undifferentiated-type histology: a meta-analysis. World J Gastroenterol 2015;21:6032-6043.

13. Kim JH, Kim YH, Jung DH, et al. Follow-up outcomes of endoscopic resection for early gastric cancer with undifferentiated histology. Surg Endosc 2014;28:2627-2633.

14. Okada K, Fujisaki J, Yoshida T, et al. Long-term outcomes of endoscopic submucosal dissection for undifferentiated-type early gastric cancer. Endoscopy 2012;44:122-127.

15. Kamada K, Tomatsuri N, Yoshida N. Endoscopic submucosal dissection for undifferentiated early gastric cancer as the expanded indication lesion. Digestion 2012;85:111-115.

16. Liberati A, Altman DG, Tetzlaff J, et al. The PRISMA statement for reporting systematic reviews and meta-analyses of studies that evaluate health care interventions: explanation and elaboration. J Clin Epidemiol 2009;62:e1-e34.

17. Kim SY, Park JE, Lee YJ, et al. Testing a tool for assessing the risk of bias for nonrandomized studies showed moderate reliability and promising validity. J Clin Epidemiol 2013;66:408-414.

18. Higgins JP, Thompson SG, Deeks JJ, Altman DG. Measuring inconsistency in meta-analyses. BMJ 2003;327:557-560.

19. Sterne JA, Egger M. Funnel plots for detecting bias in meta-analysis: guidelines on choice of axis. J Clin Epidemiol 2001;54:1046-1055.

20. Begg CB, Mazumdar M. Operating characteristics of a rank correlation test for publication bias. Biometrics 1994;50:1088-1101.

21. Lim JH, Kim J, Kim SG, Chung H. Long-term clinical outcomes of endoscopic vs. surgical resection for early gastric cancer with undifferentiated histology. Surg Endosc 2019;33:3589-3599.

22. Park JC, Lee YK, Kim SY, et al. Long-term outcomes of endoscopic submucosal dissection in comparison to surgery in undifferentiated-type intramucosal gastric cancer using propensity score analysis. Surg Endosc 2018;32:2046-2057.

23. Lee S, Choi KD, Han M, et al. Long-term outcomes of endoscopic submucosal dissection versus surgery in early gastric cancer meeting expanded indication including undifferentiated-type tumors: a criteria-based analysis. Gastric Cancer 2018;21:490-499.

24. Hahn KY, Park CH, Lee YK, et al. Comparative study between endoscopic submucosal dissection and surgery in patients with early gastric cancer. Surg Endosc 2018;32:73-86.

25. Chung MW, Jeong O, Park YK, et al. [Comparison on the long term outcome between endoscopic submucosal dissection and surgical treatment for undifferentiated early gastric cancer]. Korean J Gastroenterol 2014;63:90-98

26. Park $\mathrm{CH}$, Shin S, Park JC, et al. Long-term outcome of early gastric cancer after endoscopic submucosal dissection: expanded indication is comparable to absolute indication. Dig Liver Dis 2013;45:651-656.

27. Lee IS, Yook JH, Park YS, Kim KC, Oh ST, Kim BS. Suitability of endoscopic submucosal dissection for treatment of submucosal gastric cancers. Br J Surg 2013;100:668-673.

28. Min YW, Lee JH. Endoscopic resection for early gastric cancer beyond absolute indication with emphasis on controversial issues. J Gastric Cancer 2014;14:7-14.

29. Lee TH, Cho JY, Chang YW, et al. Appropriate indications for endoscopic submucosal dissection of early gastric cancer according to tumor size and histologic type. Gastrointest Endosc 2010;71:920-926.

30. Kang HY, Kim SG, Kim JS, Jung HC, Song IS. Clinical outcomes of endoscopic submucosal dissection for undifferentiated early gastric cancer. Surg Endosc 2010;24:509-516.

31. Choi J, Kim SG, Im JP, Kim JS, Jung HC, Song IS. Comparison of endoscopic ultrasonography and conventional endoscopy for prediction of depth of tumor invasion in early gastric cancer. Endoscopy 2010;42:705- 
713

32. Inokuchi Y, Kobayashi M, Kudo K, et al. Outcomes and precautions of endoscopic submucosal dissection for undifferentiated-type early gastric cancer. Therap Adv Gastroenterol 2015;8:255-262.

33. Kim YY, Jeon SW, Kim J, et al. Endoscopic submucosal dissection for early gastric cancer with undifferentiated histology: could we extend the criteria beyond? Surg Endosc 2013;27:4656-4662.

34. Abe S, Oda I, Suzuki H, et al. Short- and long-term outcomes of endoscopic submucosal dissection for undifferentiated early gastric cancer. Endoscopy 2013;45:703-707.

35. Kato M, Nishida T, Yamamoto K, et al. Scheduled endoscopic surveillance controls secondary cancer after curative endoscopic resection for early gastric cancer: a multicentre retrospective cohort study by Osaka University ESD study group. Gut 2013;62:1425-1432.
36. Hahn KY, Park JC, Kim EH, et al. Incidence and impact of scheduled endoscopic surveillance on recurrence after curative endoscopic resection for early gastric cancer. Gastrointest Endosc 2016;84:628-638.e1.

37. The general rules for the gastric cancer study in surgery and pathology. Part II. Histological classification of gastric cancer. Jpn J Surg 1981;11:140-145.

38. Kim DY, Park YK, Joo JK, et al. Clinicopathological characteristics of signet ring cell carcinoma of the stomach. ANZ J Surg 2004;74:10601064.

39. Hyung WJ, Noh SH, Lee JH, et al. Early gastric carcinoma with signet ring cell histology. Cancer 2002;94:78-83.

40. Adachi Y, Yasuda K, Inomata M, Sato K, Shiraishi N, Kitano S. Pathology and prognosis of gastric carcinoma: well versus poorly differentiated type. Cancer 2000;89:1418-1424. 